\title{
ADDENDUM
}

\section{Promoting pro-environmental action in climate change deniers}

Paul G. Bain, Matthew J. Hornsey, Renata Bongiorno and Carla Jeffries

Nature Climate Change 2, 600-603 (2012); published online 17 June 2012; corrected online 4 July 2012.

In the above Letter, we used the term 'denier' to describe people who are not convinced that anthropogenic climate change is occurring. The denier label refers to an image held by some in the mainstream climate science community that such people are contrarian, which other terms like 'sceptic' do not capture. We hoped our findings would suggest to mainstream climate scientists the benefit of looking beyond this contrarian image, by showing that deniers were more supportive of actions to address climate change where these actions produced beneficial social outcomes. However, since publication we were contacted by people offended by the label denier to describe their group due to its broader negative connotations. We acknowledge this point and regret any offence caused. 